\title{
Development of Image Analysis Techniques \\ as a Tool to Detect and Quantify \\ Morphological Changes in Anaerobic \\ Sludge: II. Application to a Granule \\ Deterioration Process Triggered by Contact With Oleic Acid
}

\author{
A.L. Amaral, ${ }^{1 *}$ M.A. Pereira, ${ }^{1}$ M. da Motta, ${ }^{2 \dagger}$ M.-N. Pons, ${ }^{2}$ M. Mota, ${ }^{1}$ \\ E.C. Ferreira, ${ }^{1}$ M.M. Alves ${ }^{1}$ \\ ${ }^{1}$ Centro de Engenharia Biológica, Universidade do Minho, 4710-057 Braga, \\ Portugal; telephone: + 351253604 402; fax: + 351253678 986; \\ e-mail: madalena.alves@deb.uminho.pt \\ ${ }^{2}$ Laboratoire des Sciences du Génie Chimique, CNRS-ENSIC-INPL, BP 451, \\ F-54001 Nancy Cedex, France
}

Received 22 October 2003; accepted 9 March 2004

Published online 18 June 2004 in Wiley InterScience (www.interscience.wiley.com). DOI: 10.1002/bit.20129

\begin{abstract}
Image analysis techniques are applied to monitor the morphological changes in granular sludge present in an expanded granular sludge blanket (EGSB) reactor fed with oleic acid. Deterioration of granular sludge was monitored along the trial period by measuring the percentage of aggregates smaller than $1 \mathrm{~mm}$ (in terms of Feret diameter) either in terms of projected area or in terms of number of aggregates. A good correlation was obtained between these values and the percentage of aggregates smaller than $1 \mathrm{~mm}$ were physically sorted and quantified by the volatile suspended solid content. The ratio of total filaments length to cross-sectional area of aggregates defined as $L f A$, was applied to quantify the dispersion level of the granular sludge, which increased until day 141 and remained almost invariant afterwards. $L f A$ was sensitive to the sludge deterioration process and was able to indicate, with the anticipation of about 1 month, the most significant biomass washout episode that occurred in the trial period. A mechanism of filaments' release, detachment and selective washout was proposed to explain the action of $L f A$ from this viewpoint. The equivalent diameter of the bottom aggregates larger than $1 \mathrm{~mm}$ increased with the increase on the amount of long chain fatty acids associated with the biomass by mechanisms of adsorption, precipitation, or entrapment. After a threshold value of about
\end{abstract}

Correspondence to: M.M. Alves

* Present address: Departamento de Tecnologia Química, Escola Superior de Tecnologia e de Gestão, Instituto Politécnico de Bragança, Campus de Santa Apolónia, Apartado 1038, 5301-854 Bragança, Portugal.

${ }^{\dagger}$ Present Address: Departamento de Engenharia Química, Universidade Federal de Pernambuco UFPE, Cidade Universitária, Recife, Brasil 50.740521, PE, Brasil.

Contract grant sponsors: Fundação para a Ciência e a Tecnologia (Portugal); ICCTI (Portugal); Ambassade de France (Portugal)

Contract grant numbers: PRAXIS XXI/BD/20326/99; PRAXIS XXI/BD/ 20325/99; Project No. 203 B4
200 mg COD-LCFA gVSS (COD = chemical oxygen demand; LCFA = long chain fatty acids; VSS = volatile suspended solids), a migration of granular sludge from the bottom to a top-floating layer was evident. (c) 2004 Wiley Periodicals, Inc.

Keywords: image analysis; oleic acid; granular sludge

\section{INTRODUCTION}

When fed with some problematic substrates, the stability of granules-based anaerobic reactors, such as the upflow anaerobic sludge blanket (UASB) or expanded granular sludge blanket (EGSB) reactors, is largely affected. Lipidic compounds are one of these problematic substrates. They are easily hydrolyzed to long chain fatty acids (LCFA), which adsorb onto the biomass, inducing granule disruption, flotation, and washout (Hwu, 1997). This seems to occur at concentrations far below the toxicity limit, which might suggest that complete washout of granular sludge would occur prior to inhibition. Furthermore, the addition of calcium salts prevents LCFA inhibition to some extent, but does not prevent sludge flotation (Hanaki et al., 1981).

Usually the processes of granulation and granuledisintegration are linked to a macroscopic transformation of size and morphology that can be quantified by image analysis. Although some published works are mainly focused on size determinations (Dudley et al., 1993; Jeison and Chamy, 1998), morphological parameters such as fractal dimension (Bellouti et al., 1997), and quantification of bacterial morphotypes within anaerobic granules from transmission electron micrographs (Howgrave-Graham and Wallis, 1993) are examples of application of image analysis techniques to granular sludge characterization. In a previous 
work, the number and the total length of filaments present in anaerobic sludge when exposed to oleic acid shock loads was monitored by image analysis (Alves et al., 2000).

Bacterial filamentous forms play a key role in the process of granulation (Wiegant and de Man, 1986). Therefore, the release of these forms to the bulk medium in the process of granules disruption is expected. The quantification of filaments and filaments-to-aggregates ratio ( $L f A$, defined in Araya-Kroff et al., this issue) can thus give important insights on process stability and can potentially be included in expert systems, as alert indicators, for supervision and control of high-rate anaerobic wastewater treatment.

Our aim in the present work is to apply image analysis techniques, described in detail in Part I (Araya-Kroff et al.), to detect and quantify the morphological changes in granular sludge. In this case a process of granules deterioration triggered by the contact with oleic acid is monitored.

\section{MATERIALS AND METHODS}

\section{EGSB Reactor and Operation Mode}

An EGSB reactor similar to the one described in Part I, with a volume of $10 \mathrm{~L}$ was fed with increasing oleate concentrations between 2 and $8 \mathrm{~g} \mathrm{COD} \mathrm{L,} \mathrm{at} \mathrm{an} \mathrm{HRT} \mathrm{of} 1 \mathrm{~d}$. The operation of this reactor was described previously (Pereira et al., 2002); Table I summarizes the steady-state operating conditions and performance during the trial period.

Temperature was kept constant at $37 \pm 1^{\circ} \mathrm{C}$. A recycling rate of $14 \mathrm{~L} / \mathrm{d}$ was applied.

\section{Routine Analysis}

Routine reactor performance was monitored by determining influent and effluent total and soluble (centrifuged $10 \mathrm{~min}$ at 15,000 rpm) chemical oxygen demand (COD), influent flow rate, methane production, and volatile suspended solids (VSS). Chemical oxygen demand and VSS were determined according to standard methods (APHA et al., 1989). Biogas flow rate was measured by a Shinagawa Seiki DC1C dry test gas meter (Shinagawa Corp., Tokyo, Japan). Methane content of the biogas was determined by gas chromatography using a Haysep Q (80-100 mesh) column (Chrompack, Middelburg, The Netherlands), with $\mathrm{N}_{2}$ carrier gas at $30 \mathrm{~mL} / \mathrm{min}$ and a flame-ionization detector. Temper- atures of the injection port, column, and flame-ionization detector were 120,40 , and $130^{\circ} \mathrm{C}$, respectively. Biogas samples were analyzed in triplicate and the results average expressed as a percentage of methane by calibration against standards of $50 \%(\mathrm{v} / \mathrm{v})$ methane/air.

\section{Seed Sludge and Substrate}

Granular sludge, obtained from an UASB treating a brewery effluent, was used as seed sludge-1.6 L (20.2 g VSS L) were inoculated. The inoculum was characterized in terms of size and morphological characteristics. The average equivalent diameter of the aggregates larger than $1 \mathrm{~mm}$ was $1.59 \pm$ $0.07 \mathrm{~mm}$ and the average equivalent diameter of the aggregates smaller than $1 \mathrm{~mm}$ was $0.184 \pm 0.008 \mathrm{~mm} .46 .5 \%$ of the total projected area accounted for aggregates larger than $1 \mathrm{~mm}$. The ratio between the total filament length and the total area of aggregates ( $L f A)$ was $37.7 \mathrm{~mm}^{-1}$.

For the first 70 days, the substrate consisted of skim milk (50\% COD) and sodium oleate (50\% COD) diluted with tap water. From day 70 on, the carbon source was exclusively composed of sodium oleate, supplemented with macro- and micronutrients and $\mathrm{NaHCO}_{3} / \mathrm{L}$ as described in Part I.

\section{Batch Experiments}

Some of the samples characterized by image analysis were characterized for the amount of biomass-associated LCFA in batch tests as previously described by Pereira et al. (2002). Table II summarizes the obtained values for the maximum plateaux, which are estimates of the amount of LCFA that accumulated on the sludge.

\section{Auto-Fluorescence Observations}

A Zeiss Axioscop microscope (Zeiss, Oberkochen) equipped with a ZEISS AxioCam HRc digital camera was used to examine the auto fluorescence of the sludge samples at $420 \mathrm{~nm}$.

\section{Sludge Sampling and Processing for Image Analysis}

The sludge inside the reactor was segregated into two layers: a heavy bottom layer and a top-floating layer, located in the top of the reactor, at liquid-gas interface. Sludge samples for image analysis were taken on days 70 ,

Table I. Operating conditions and performance (mean $\pm 95 \%$ confidence intervals).

\begin{tabular}{lccccccc}
\hline Period & Time (d) & HRT (d) & $\begin{array}{c}\text { Influent } \\
\text { COD }(\mathrm{g} / \mathrm{L})\end{array}$ & $\begin{array}{c}\text { Influent } \\
\text { oleate COD }(\mathrm{g} / \mathrm{L})\end{array}$ & $\begin{array}{c}\text { COD Removal } \\
\text { efficiency }(\%)\end{array}$ & $\begin{array}{c}\text { Effluent } \\
\text { VSS }(\mathrm{g} / \mathrm{L})\end{array}$ & $\begin{array}{c}\text { Methane production } \\
(\mathrm{L} \mathrm{CH} /(\mathrm{L} \mathrm{d}))\end{array}$ \\
\hline I & $0-70$ & $1.01( \pm 0.01)$ & $3.8( \pm 0.3)$ & $1.9( \pm 0.2)$ & $96.5( \pm 0.6)$ & $0.38( \pm 0.07)$ & $1.06( \pm 0.1)$ \\
II & $70-119$ & $1.01( \pm 0.01)$ & $3.8( \pm 0.3)$ & $3.8( \pm 0.3)$ & $83.4( \pm 4.8)$ & $0.85( \pm 0.22)$ & $0.23( \pm 0.05)$ \\
II & $119-162$ & $1.01( \pm 0.01)$ & $6.2( \pm 0.7)$ & $6.2( \pm 0.7)$ & $74.2( \pm 3.8)$ & $1.96( \pm 0.43)$ & $0.16( \pm 0.02)$ \\
IV & $162-219$ & $1.01( \pm 0.01)$ & $8.2( \pm 0.5)$ & $8.2( \pm 0.5)$ & $68.8( \pm 3.4)$ & $2.71( \pm 0.57)$ & $0.15( \pm 0.02)$ \\
\hline
\end{tabular}


Table II. Maximum plateau obtained in the batch experiments (Mean $\pm S D)^{\mathrm{a}}$

\begin{tabular}{lcc}
\hline & \multicolumn{2}{c}{$\begin{array}{c}\text { Biomass-associated LCFA } \\
\left(\mathrm{mg} \mathrm{COD}-\mathrm{CH}_{4} / \mathrm{gVSS}\right)\end{array}$} \\
\cline { 2 - 3 } & Bottom & Top \\
\hline Day 70 & $263 \pm 17$ & $276 \pm 87$ \\
Day 119 & $97 \pm 34$ & $434 \pm 17$ \\
Day 162 & $97 \pm 6$ & $997 \pm 109$ \\
Day 219 & $51 \pm 3$ & $100 \pm 11$ \\
\hline
\end{tabular}

${ }^{\text {a}}$ Adapted from Pereira et al., 2002.

92, 119, 141, 162, 191, and 219 from both layers. For all the samples, the VSS content was determined as well as the percentage of small aggregates, determined by the ratio between the VSS that could be removed using a syringe equipped with a $20 \mathrm{G} \times 1^{\prime \prime}$ needle (internal diameter = $0.9 \mathrm{~mm}$ ), and the total VSS.

\section{Image Acquisition and Analysis}

Filaments, micro- and macro-aggregates were quantified by image analysis, using the procedures and programs already described in Part I (Araya-Kroff et al.).

\section{RESULTS AND DISCUSSION}

The tentative monitoring of granules deterioration by the average equivalent diameter was unsuccessful. The aggregates were then classified in size ranges. In addition, a physical separation was applied as described in the Materials and Methods section by removing the smaller aggregates with a syringe equipped with a needle $(0.9-\mathrm{mm}$ internal diameter) and by quantifying the VSS content of each fraction. The breadth of the largest particle that could enter the needle was determined by image analysis using the minimal Feret diameter concept (Russ, 1995) and corresponded to $1 \mathrm{~mm}$, which is understandable given the deformable nature of sludge aggregates. The minimal Feret diameter (minFD) is the minimum distance between parallel tangents touching opposite sides of an object (Fig. 1).

Size ranges were therefore categorized according to their Feret diameters. Small aggregates had a minimum Feret diameter (minFD) smaller than $1 \mathrm{~mm}$ and large aggregates had a minFD larger than $1 \mathrm{~mm}$.

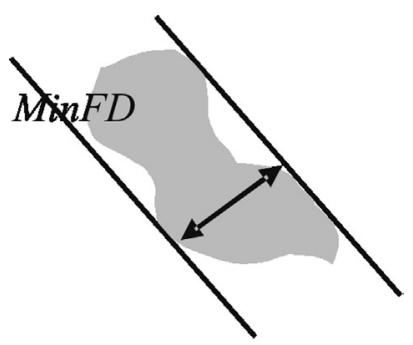

Figure 1. Definition of the minimum Feret diameter (minFD).
Figure 2a shows the change in the percentage of small aggregates in terms of their projected area, number of particles, and physical separation described in the Material and Methods section, as well as the percentage of VSS of each fraction. These results represent average values between two segregated bottom and top layers of sludge that were formed in the reactor.

It is evident that size reduction of granules occurred along the trial period, as the fraction of small aggregates increased steadily, whatever the method used for its determination. With the single exception of one experimental point, an acceptable correlation was found between the percentage of small aggregates determined by the physical separation method and by the image analysis techniques (Fig. 2b).

The ratio between the total filament length and the total area of aggregates ( $L f A)$, defined and applied to identify aggregation time (Araya-Kroff et al.), was also applied to the sludge taken from the bottom and from the top of the reactor (Fig. 3a). The time course of effluent VSS concentration is also presented (Fig. 3b).

A morphological stratification occurred within the reactor, with a significantly higher filaments-to-aggregates ratio in the top than in the bottom layer, from day 100 onward. After day 140, the morphological structure in terms of filaments-to-aggregates ratio remained approximately invariant for both sections. The maximum values detected in
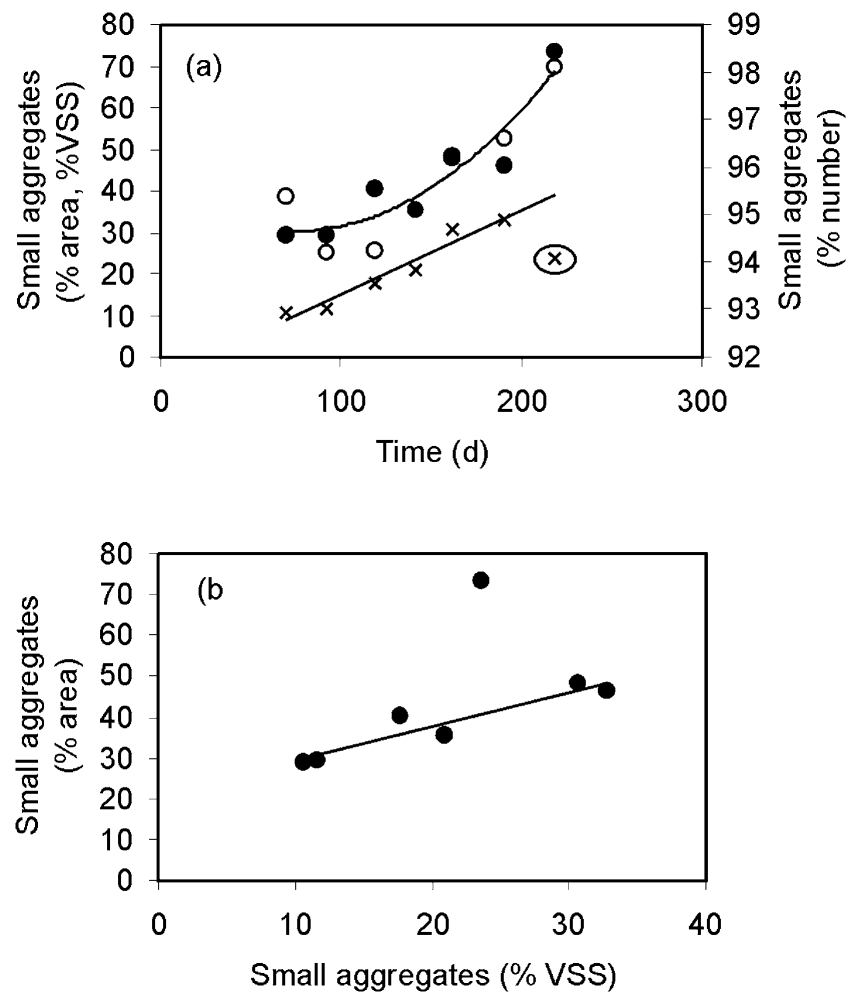

Figure 2. (a) Time course of the ratio of small aggregates determined by weight $[(\times) \%$ VSS $]$ and determined by image analysis $[(0) \%$ number, $(\bullet)$ $\%$ projected area]. (b) Correlation between the image analysis method and the physical separation method based on the weight of VSS. Marked point was not taken into account for the correlation. 

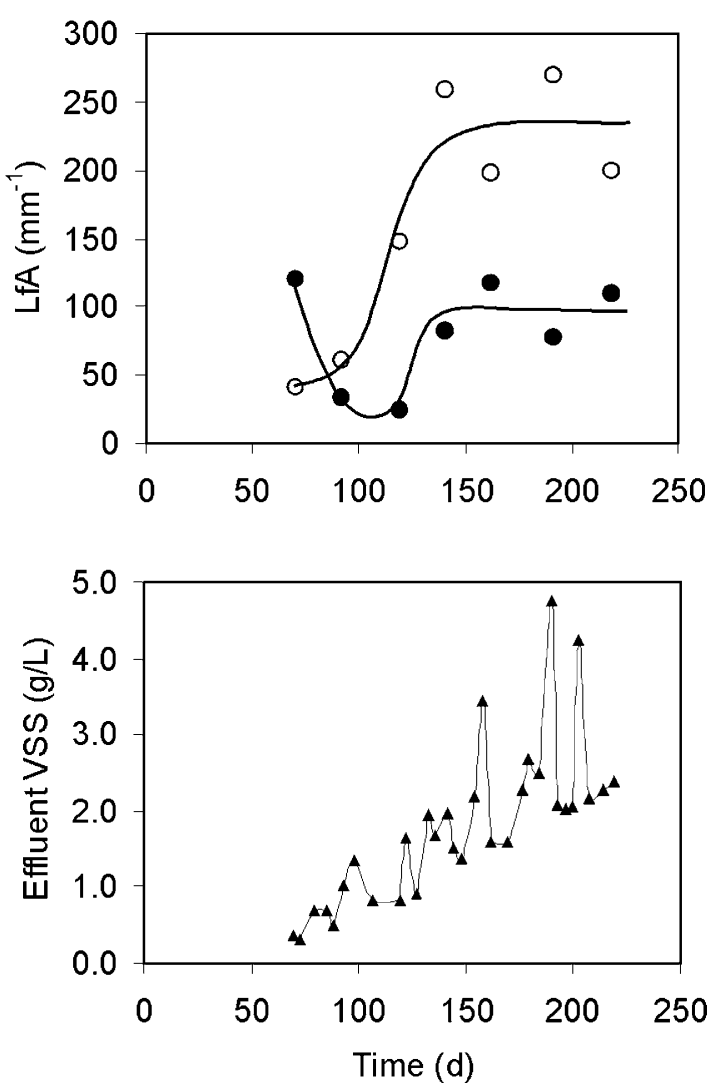

Figure 3. Time course of the ratio between the total free filament length and the total projected area of aggregates ( $L f A)$ in the bottom and top sludge layers and effluent VSS concentration (b). ( ) bottom, $(O)$ top.

the granulation study (Part I) and in the present work are in the same range (about $280 \mathrm{~mm}^{-1}$ ).

An important aspect is the relative change of $L f A$ and effluent VSS along the operation, since it was hypothesized that $L f A$ could be an early alert of washout (Araya-Kroff et al.). Comparing Figure $3 \mathrm{a}$ and $3 \mathrm{~b}$ it can be observed that, in the period between days 100 and 140, LfA in the top layer increased about 6 times, from 40 to $250 \mathrm{~mm}^{-1}$. In the same time period the VSS increased moderately from a minimum of 0.81 to a maximum of $1.97 \mathrm{~g} / \mathrm{L}$ with an average value of $1.3 \pm 0.5 \mathrm{~g}$ VSS L. From the day 140 on, the LfA remained oscillating between 200 and $270 \mathrm{~mm}^{-1}$, but the effluent VSS concentration showed the most significant increase oscillating between a minimum of $1.4 \mathrm{~g}$ VSS L and a maximum of $4.8 \mathrm{~g}$ VSS L with an average value of $2.4 \pm$ $0.9 \mathrm{~g}$ VSS L.

Data from Tables I and II allowed estimating the fraction of VSS that is due to the accumulation of LCFA on the biomass. A maximum value of $30 \%$ was found. Even after correction of the observed effluent VSS concentration a large biomass washout could be detected (for instance, for the maximum value of VSS, about $3.36 \mathrm{gVSS}$ L corresponded to biomass-VSS and $1.44 \mathrm{gVSS} \mathrm{L}$ accounted for the biomass-associated LCFA). LfA was, in this case, sensitive to the sludge deterioration process and was able to indicate, with the anticipation of about 1 month, the most significant biomass washout episode that occurred in the reactor operation. This potential capacity of $L f A$ to predict washout events is of paramount importance from a practical viewpoint.

The release of filaments simultaneous with the fragmentation induced by the contact with oleic acid seems to be a reasonable explanation for the increase in $L f A$ in the top sludge, between days 100 and 140. However, the evolution of filaments and small aggregates did not follow similar trends during the operation of the reactor. Although the relative amount of small aggregates increased steadily all along the operating period, the ratio between filaments and aggregates ( $L f A)$, remained almost constant after day 140, which is likely because filaments, especially those that are not linked to any fragment of granule, could have been selectively washed out from the reactor. The small aggregates which can be fragments of granules that still have granular properties in terms of density, notwithstanding the smaller size, may have been retained inside the reactor.

The relationship between the parameter $L f A$ and the $\%$ of small aggregates (\% projected area) is evidence of the relative importance between fragmentation and filaments release during the process of granules deterioration (Fig. 4).

When granules start to fragment (for a relatively low percentage of small aggregates), an increase in the release of filaments to the medium was observed, especially in the top layer. These filaments can still be attached to the aggregates. After a certain degree of fragmentation (percentage of small aggregates higher than about 38\%), the ratio filaments/ aggregates became approximately independent of the percentage of small aggregates, probably because detachment and selective washout of filaments occurred. The dynamics of fragmentation, filaments release, and washout is described in the schematic chronogram of Figure 5.

As the oleate loading rate increased, more LCFA accumulated onto the sludge. The amount of LCFA associated to the biomass by mechanisms of adsorption, precipitation, or entrapment was determined in batch assays as described elsewhere (Pereira et al., 2002). The accumulation of LCFA onto the granular sludge is reported to in-

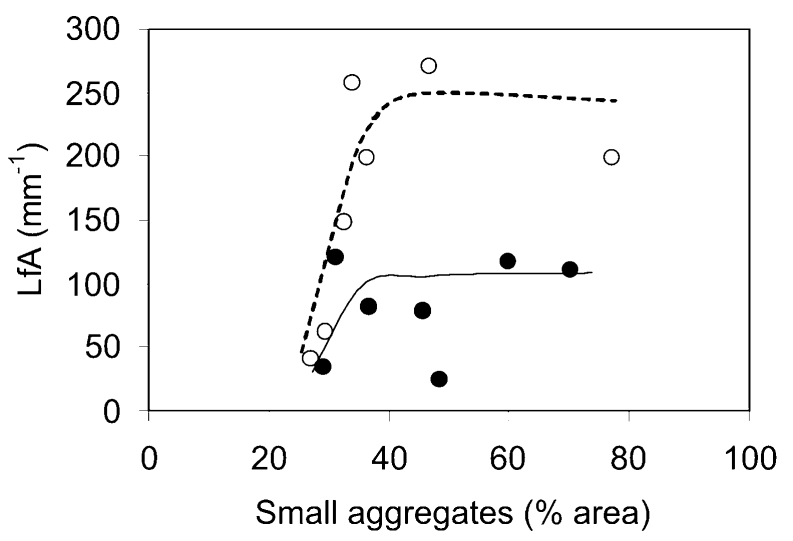

Figure 4. Relationship between $L f A$ and the percentage of small aggregates in terms of projected area. ( ) bottom, (O) top. 


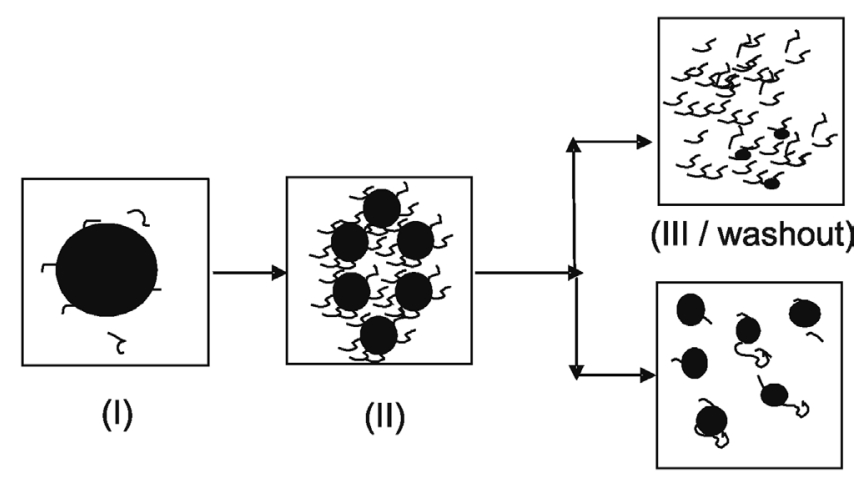

(IV)

Figure 5. Schematic chronogram of filament release, fragmentation, and washout. I-granule; II-fragmentation and filaments release, increase in LfA; III—detachment and selective washout of filaments; IV—permanence of small aggregates inside the reactor.

duce granular deterioration. According to Daffonchio et al. (1995), from a thermodynamic viewpoint the aggregation of hydrophobic bacteria, like most acetogens (LCFA-degraders) is hindered and disintegration of granules is predictable, since at neutral $\mathrm{pH}$, LCFA act as surfactants, lowering the surface tension. Sam-soon et al. (1991) used a UASB reactor to treat oleate as a unique carbon source and reported that the original inoculated pellets suffered from disintegration and encapsulation by a gelatinous and whitish mass. In Figure 6 an example of granule deterioration is shown. The decrease of the visible auto fluorescence of the methanogenic population as a result of a light emission barrier caused by the accumulation of LCFA onto the sludge can also be observed.

Figure 7 represents the effect of the amount of accumulated (biomass-associated) LCFA on the average equivalent diameter of the larger aggregates (minFD $>1 \mathrm{~mm}$ ).

In the bottom sludge the maximum amount of accumulated LCFA was about one fourth of the maximum determined in the top sludge (Table II). It is accepted that adsorption of LCFA induces biomass flotation (Hwu, 1997) and consequently higher amounts of adsorbed sub-

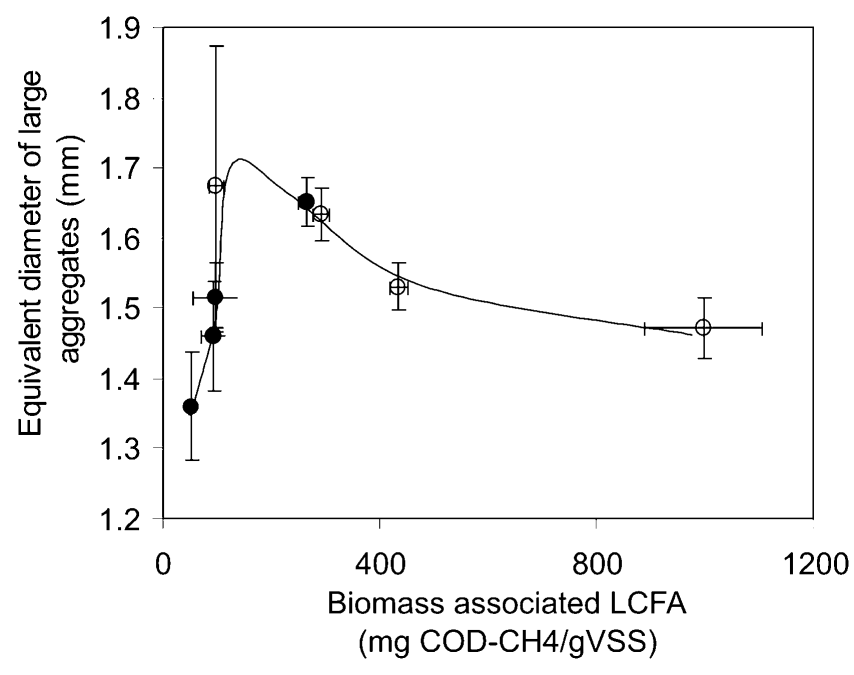

Figure 7. Effect of the accumulated (biomass-associated) LCFA on the average equivalent diameter of non-fine aggregates. $(\bullet)$ bottom, (O) top.

strate were expected in the top sludge. Figure 7 shows that when the biomass-associated LCFA increased up to $200 \mathrm{mg}$ COD- $\mathrm{CH}_{4}$ gVSS the larger aggregates present in the bottom, also increased in size. When the amount of accumulated LCFA was higher than this value, the aggregates migrated to the top layer due to a decrease in the overall density. From this figure, the definition of the threshold value of biomass-associated LCFA that originates this migration is of practical interest, since the top sludge in this type of reactor is primarily condemned to be washed out. Hwu (1997) also studied the problems of washout in EGSB reactors fed with an oleic-acid based effluent. He concluded that typical operating parameters of EGSB reactors (superficial velocity higher than $4 \mathrm{~m} / \mathrm{h}$ and hydraulic retention time lower than $10 \mathrm{~h}$ ) inhibited the treatment performance of LCFA containing wastewaters. In that case, washout problems were more acute than toxicity problems. He found that for an EGSB reactor operated at an HRT between 16 and $27.6 \mathrm{~h}$, sludge flotation started occurring for a specific organic load of $86 \mathrm{mg} \mathrm{COD} /(\mathrm{gVSS}$ d) (corresponding
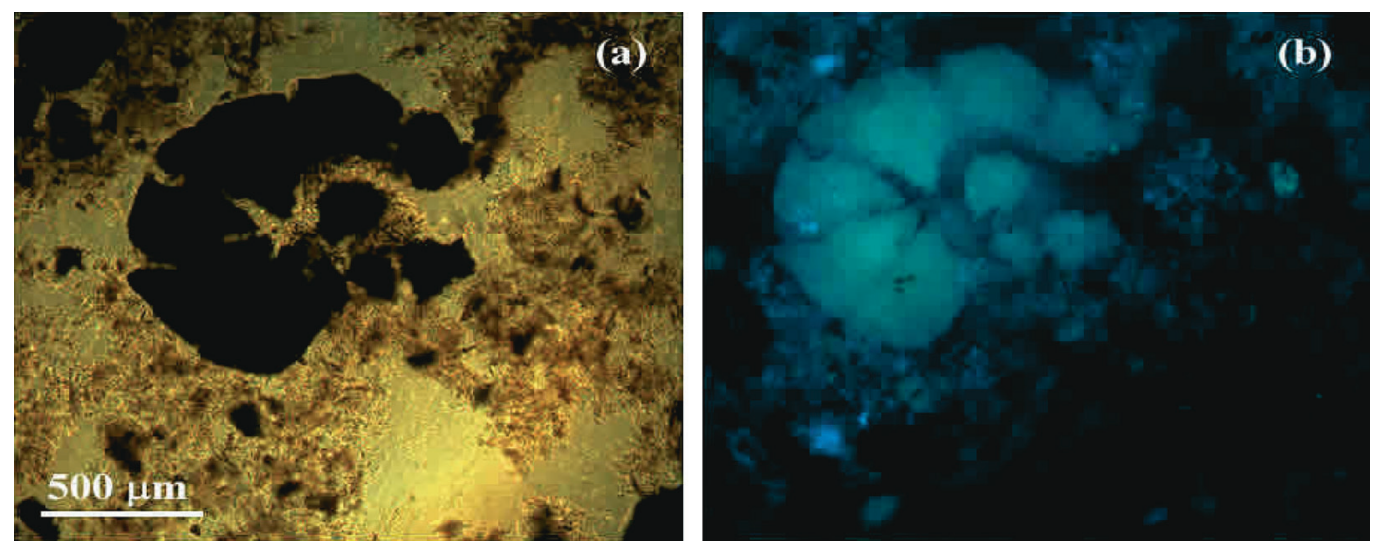

Figure 6. Typical microscopic aspect of the granular sludge present in the top layer (day 219) showing: (a) granule fragmentation and (b) autofluorescence of methanogenic bacteria at $420 \mathrm{~nm}$. 
to a value of $98.9 \mathrm{mg}$ COD $\mathrm{gVSS}$ ) and complete flotation occurred for a specific organic load of $203 \mathrm{mg} \mathrm{COD/}$ (gVSS d), which corresponds to about $140 \mathrm{mg}$ COD gVSS. The threshold value that induced sludge flotation, in the present work (Fig. 7), is in the same range of those reported by Hwu (1997).

\section{CONCLUSIONS}

Deterioration of granular sludge induced by the prolonged contact with oleic acid was morphologically quantified by the percentage of aggregates smaller than $1 \mathrm{~mm}$ either in terms of projected area or in terms of number of aggregates. A linear correlation was obtained between these values and the percentage of aggregates smaller than $1 \mathrm{~mm}$ physically sorted and quantified by the VSS content. A morphological parameter relating the amount of free filaments and the projected area of aggregates $(L f A)$ already used to detect the aggregation time in Part I, was used to quantify the dispersion level of the granular sludge, which increased until day 141 and remained almost invariant afterwards. When oleic acid concentration increased, LfA was sensitive to the sludge deterioration process and was able to indicate, with the anticipation of about 1 month, the most significant biomass washout episode that occurred in the trial period. A mechanism of filaments release, detachment, and selective washout was proposed to explain the effect on LfA. The equivalent diameter of the bottom aggregates larger than $1 \mathrm{~mm}$ increased with the increase on the amount of accumulated LCFA. After a threshold value of about $200 \mathrm{mg}$ COD- $\mathrm{CH}_{4} \mathrm{gVSS}$, the aggregates migrated to the top-floating layer, thus proving the practical interest of this threshold value as far as the continuous operation of sludge bed reactors with LCFA based effluents, is concerned.

The potential capacity of $L f A$ to predict washout events is of paramount importance from a practical viewpoint.

We grateful acknowledge the financial support to Alcina Pereira and Luís Amaral through the grants PRAXIS XXI/BD/20326/99, and PRAXIS XXI/BD/20325/99, respectively, from the Fundação para a
Ciência e a Tecnologia (Portugal). The ICCTI (Portugal) and Ambassade de France in Portugal provided financial support for cooperation between Braga and Nancy teams through project no. 203 B4.

\section{References}

Alves MM, Cavaleiro AJ, Ferreira EC, Amaral AL, Mota M, da Motta M, Vivier H, Pons M-N. 2000. Characterization by image analysis of anaerobic sludge under shock conditions. Wat Sci Technol 41:207-214.

APHA, AWWA, WPCF. 1989. Standard methods for the examination of water and wastewater, 17th ed. Washington, DC: American Public Health Association.

Araya-Kroff P, Amaral AL, Neves L, Ferreira EC, Pons M-N, Mota M, Alves MM. 2004. Development of image analysis techniques as a tool to detect and quantify morphological changes in anaerobic sludge: I. Application to a granulation process. Biotechnol Bioeng 87:184-193.

Bellouti M, Alves MM, Novais JM, Mota M. 1997. Flocs vs granules: Differentiation by fractal dimension. Wat Res 31:1227-1231.

Daffonchio D, Thaveesri J, Verstraete W. 1995. Contact angle measurement and cell hydrophobicity of granular sludge from upflow anaerobic sludge bed reactors. Appl Env Microbiol 61:3676-3680.

Dudley BT, Howgrave-Graham AR, Bruton AG, Wallis FM. 1993. Image analysis to quantify and measure UASB digester granules. Biotechnol Bioeng 42:279-283.

Hanaki K, Matsuo T, Nagase M. 1981. Mechanisms of inhibition caused by long chain fatty acids in anaerobic digestion process. Biotechnol Bioeng 23:1591-1560.

Howgrave-Graham AR, Wallis FM. 1993. Quantification of bacterial morphotypes within anaerobic digester granules from transmission electron micrographs using image analysis. Biotechnol Lett 7:143-148.

Hwu C-S. 1997. Enhancing anaerobic treatment of wastewaters containing oleic acid. Ph.D. Thesis, Wageningen Agricultural University, The Netherlands.

Jeison D, Chamy R. 1998. Novel technique for measuring the size distribution of granules from anaerobic reactors for waste-water treatment. Biotechnol Tech 12:659-662.

Pereira MA, Pires OC, Mota M, Alves MM. 2002. Anaerobic degradation of oleic acid by suspended and granular sludge: Identification of palmitate as a key intermediate. Wat Sci Technol 45:139-144.

Russ JC. 1995. The image processing handbook. Boca Raton, FL: CRC Press.

Sam-soon P, Loewenthal RE, Wentzel MC, Marais GR. 1991. A longchain fatty acid, oleate, as sole substrate in upflow anaerobic sludge bed (UASB) reactor systems. Water SA 17:31-36.

Wiegant W, de Man A. 1986. Granulation of biomass in thermophilic upflow anaerobic sludge blanket reactors treating acidified wastewaters. Biotechnol Bioeng 28:718-727. 